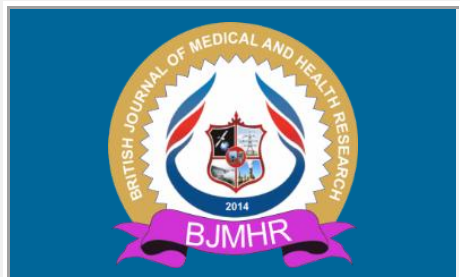

\title{
BJMHR
}

British Journal of Medical and Health Research Journal home page: www.bjmhr.com

\section{Effect of K-Taping with Therapeutic Ultrasound on Hamstring Avulsion Injury-Case Report}

\author{
Shabana Khan ${ }^{1 *}$, Nourah Al Muhanna ${ }^{2}$ \\ 1.Physiotherapist at female Ortho OPD at Prince Sultan Military Medical City-Riyadh- \\ $K S A$ \\ 2. Clinical Supervisor, at female Ortho OPD at Prince Sultan Military Medical City- \\ Riyadh-KSA
}

\begin{abstract}
Rehabilitation of sports related hamstring injuries is challenging as it requires safe and early return to sport. This is because hamstring injuries need time to recover and has high rate of re injury. In our case report, 21- year-old female student, involved in sports activity (weight lifting), who was rehabilitated for left hamstring avulsion injury was briefed to report and elucidate the importance of hamstring injury treatment conservatively and to describe a rehabilitation program on athletes with clinical outcome. She was conservatively treated with K-Tape with therapeutic ultrasound, twice a week, once a day for three weeks duration. At the end of third of intervention- pain, muscle strength and range of motion was assessed. She had no impairment or functional limitations, including full range of pain-free movement of left leg, pain $0 / 10$ by VAS score. By the $4^{\text {th }}$ week, she started to perform sports specific drills. She was rehabilitated and set fit to play after 6 weeks from the date of injury. K-Tape with therapeutic ultrasound is effective in hamstring injuries. In this case study, rehabilitation program with an emphasis on K-Tape with therapeutic ultrasound is found to be effective in returning the weight lifter back to play.
\end{abstract}

Keywords: K-Tape, Ultrasound, rehabilitation, stretching exercise 


\section{INTRODUCTION}

Hamstring muscle strain is a frustrating injury, well known to medical staff, coaches, and athletes. It is frustrating because the symptoms are persistent, healing is slow, and the rate of re injury is high ${ }^{1}$.

An athletes can have hamstring injury in wide variety, including strains, complete or partial avulsions of proximal hamstring tendon or is chial apophysis, proximal hamstring tendinitis, and referred pain in posterior thigh ${ }^{2,3}$. These, hamstring strains are the most prevalent hamstring-related injury resulting in loss of time for athletes at all levels of competition ${ }^{2-8}$. Elkstrand et al. demonstrated that hamstring injuries account for $37 \%$ of total muscle injuries in football players and for $25 \%$ of athlete's absence in games. Other studies indicate that onethird of hamstring injuries relapse and that many of these relapses take place within the first two weeks after returning to sport ${ }^{9,5,10}$. The aims for these injuries rehabilitation are to reach the same level of function as found before injury and to allow athletes to return to previous sport with minimum risk of recurrence ${ }^{11}$. Many interventions are widely used to achieve full rehabilitation. These include PRICE (protection, rest, ice, compression, and elevation), to control the inflammatory process ${ }^{12}$; therapeutic exercises to strengthen and restore the functionality of the musculature ${ }^{13}$; photo thermal therapy for inflammation modulation; massage and mobilization to realign and relieve tension of soft tissues; manual therapy for joint and nerve; and functional rehabilitation. However, evidence of the effectiveness of these treatment modalities is not yet fully established, due to the sparse scientific research on the subject $^{14}$. Hamstrings are the long and powerful group of muscles that span the back of the thigh. The collective term "hamstrings" refers to four muscles (semitendinosus, semimembranosus, long and short head of biceps femoris) located in the posterior compartment of the thigh. In European elite football, hamstring injury is the most common diagnosis: $12 \%$ of all injuries are hamstring injuries ${ }^{15}$.

In general, it is believed that hamstring injuries occur primarily during activities or sports that demands extreme speed and power. However, recent studies suggest that hamstring strain or injuries can occur also in slow speed stretching exercises ${ }^{16}$.

Sun-Min and Jung-Hoon Lee, 2018. use K-Tape on his study to know, effects of balance taping on hamstring muscle injury and traumatic knee pain incurred by an amateur university football player as a result of tackling during a football game ${ }^{17}$. Therapeutic ultrasound can work as either a superficial or a deep heating modality depending on the frequency used. While $3 \mathrm{MHz}$ ultrasound (US) provides superficial heating, $1 \mathrm{MHz}$ US heats tissues at depths of $3-5 \mathrm{~cm}$ and is considered to be a deep heating agent. US produces heat through high frequency acoustic 
vibrations. This type of energy transmission that it is minimally hindered by adipose tissue due to its high water content ${ }^{18}$.

The research regarding effects of $\mathrm{K}$ Taping (KT) along with therapeutic ultrasound on hamstring avulsion injury is lacking and is not enough, so we are describing a case of a hamstring injury to know the effect of KT with US on hamstring injury.

\section{CASE REPORT}

A 21-year-old student female patient who involved in sports activity (weight lifting), suffering from pain in the posterior thigh since one month. She reveals history of lifting heavy weight in splinting like position, developed severs pain in left buttock. She attended emergency ward. Physical examination revealed ecchymosis on proximal posterior part of thigh and advised by physician to apply ice on injured area for 10 min 2-3 times a day along with a non-steroidal anti-inflammatory drug. A diagnosis of partial hamstring avulsion injury was made one the basis of MRI report and referred to physical therapy department for conservative treatment. During triage in physiotherapy department her overall health was excellent. She cleared all red flags and appointed as urgent case in orthopedic outpatient department of physiotherapy. On the day of assessment she showed no symptoms of swelling, gait deviation, numbness and tingling. However, decreased stability when trying to balance on left leg. She reported a score of 6/10 on Visual Analog Scale (VAS) (where 0 indicates no pain and 10 maximum possible pains) for pain, normal range of motion and muscle power of $4 / 5$ for left leg, before intervention. The patient was treated for hamstring injury with K-Taping along with ultrasound, with strengthening exercise protocol for 6 sessions, 2 times per week, once a day for 3 weeks. Anti-inflammatory drug previously taken with slight improvement in symptoms. The main aim for physiotherapy included decreasing pain, improving muscle strength, balance and return to sport.

\section{TREATMENT}

Patient was treated with Enraf-Nonius 434 ultrasound therapy device, with continuous therapeutic ultrasound, was administered 2 times/week for 3 weeks for 6 sessions. The ultrasound treatment was administred with a power of $0.8 \mathrm{~W} / \mathrm{cm} 2$, a frequency of $1 \mathrm{MHz}$, continuously, $7 \mathrm{~min}$ on the proximal hamstrings near ischeal tuberosity ${ }^{19}$, after ultrasound therapy stretching was applied immediately. The stretching exercise was carried out as follows: Starting Position: patient assumed the full supine -lying position on a plinth with her two feet pointing upwards. The contra-lateral lower limb was securely strapped to the plinth using 2 slings positioned across the thigh and over the anterior superior iliac spine to stabilize the pelvis. The lower limb being stretched was passively moved into the extreme of extension, up 
to the limit where the patient felt a gentle stretch at the posterior aspect of the thigh. This placed the hamstring muscles at their greatest possible length. The stretch was sustained for 30 seconds, after stretching exercises K-Tape is applied by using pink color $5 \mathrm{~cm}$ wide kinesio tape to the hamstrings using the $\mathrm{Y}$-shaped taping technique ${ }^{20-21}$. K-tape was applied un stretched to the neutral body position, on the semitendinosus, semimembranosus, and biceps femoris of the hamstring muscles of the left lower extremities in order to achieve a relaxing effect. $^{22}$. To use the correct length of the tape for patient, were measured in a stretched position from the medial or lateral condyle of the tibia to the ischial tuberosity. The patient was advised to perform combination of weight-bearing and non-weight-bearing exercises. Initial program consisted of the following 2 exercises, performed 1 to 2 times daily, using controlled motions and a slow eccentric phase over approximately 5 seconds: seated hamstring curls and supine hamstring curls. The patient was instructed to perform the eccentric strengthening to the point of reproducing his typical tendon pain, as long as the pain was not progressively getting worse or disabling. Three sets of 15 repetitions were to be performed for each exercise as home exercise program.

The procedure was carried out twice a week for 3 consecutive weeks. There was no pain $(0 / 10)$ reported on VAS after intervention and no impairment or functional limitations, including normal range of motion of left leg.

\section{DISCUSSION}

The patient reported no pain, muscle power of 5/5 and full range of motion of left leg during activities of daily living. She was able to resume her sports without pain. There was significant reduction in pain after K-tape session with therapeutic ultrasound.

Lee and Choi 2016, suggested during a football game, the knees and hamstring muscles are particularly more vulnerable to injury ${ }^{23}$. Sun-Min, Jung-Hoon Lee 2018, were used balance taping technique and test methods to treat pain caused by hamstring muscle and traumatic knee flexion injuries. Because the hamstring muscle is the primary source of movement during knee flexion, which caused pain in our patient, a contact test was performed for the hamstring muscle prior to balance taping to confirm whether hand contact decreased pain during knee flexion. Subsequently, tactile stimulation was provided by kinesiology tape, instead of the hands, to the semimembranosus and biceps femoris, which form the hamstring muscle ${ }^{17}$. The application of kinesiology tape enhances proprioception by stimulating cutaneous mechanoreceptors ${ }^{17,24}$. Merino et al. (2010) in a pilot study with 10 healthy male triathletes (age $29.40 \pm 9.07$ years) on lower back and hamstring flexibility found significant improvement $(\mathrm{p}<0.05)$ as a result of the use of KT measured by the SRT ${ }^{25}$. Yoshida and Kahanov (2007) in a study on the effect of KT in the ROM of the trunk carried out on 30 healthy university student volunteers ( 15 females 
$26.9 \pm 5.9$ years, 20 males and $15.9 \pm 12.1$ years), observed that there were significant differences $(\mathrm{p}<0.05)$ in the ROM of the trunk flexors measured with toe touch test. However, they found no significant differences $(\mathrm{p}>0.05)$ in the scores of the lateral flexion and trunk extension $^{26}$.

Kendall et al., 2007; Travell and Simons, 2004, found of the effectiveness of KT on flexibility might be more effective for people with muscle shortness. Looking at results obtained in this research, we encountered students clearly within the normal hamstring extensibility range ${ }^{27,28}$. Emad T Ahmed 2014, found on his study that static stretching was effective in increasing hamstring flexibility which coincide with other study ${ }^{19}$ which stated that passive static stretching is the best option for the improvement of both active and passive range of motion. Two mechanisms are essentially considered responsible for ROM increase after muscle stretching: in the first one, an alteration in the sensitivity of pain receptors increases stretching tolerance and, consequently, the effectiveness of the techniques ${ }^{29}$, and in the second one, changes in tissue viscoelasticity, such as the decrease in the passive tension of the muscle tendon unit immediately after stretching, are the primary reasons for the flexibility gain ${ }^{30}$.

US can be used to target the collagen-rich tendinous units of the hamstring muscles because of its ability to penetrate deeper tissues. Several researchers have demonstrated the beneficial effects of heat on collagenous tissue $\mathrm{e}^{31,32}$.

Funk et al performed a study comparing MHP treatments without a stretch and a stretching routine alone on hamstring extensibility. They found that MHP treatments resulted in significant increases in hamstring extensibility compared with the stretching routine. Because we found no significant difference between MHP and US treatments, it can be inferred that an US treatment would also be more effective than a stretching routine ${ }^{33}$.

All the above study strongly supports our result.

\section{REFERENCES}

1. J Petersen, P Holmich, Evidence based prevention of hamstring injuries in sport,_Br $\mathbf{J}$ Sports Med: first published as 10.1136/bjsm.2005.018549 on 23 May 2005.

2. Sherry M. Examination and treatment of hamstring related injuries. Sports Health 2012; 4:107-14.

3. Sherry MA, Johnston TS, Heiderscheit BC. Rehabilitation of acute hamstring strain injuries. Clin Sports Med 2015; 34:263-84.

4. Sanfilippo JL, Silder A, Sherry MA, Tuite MJ, Heiderscheit BC. Hamstring strength and morphology progression after return to sport from injury. Med Sci Sports Exerc $2013 ; 45: 448-54$. 
5. Sherry MA, Best TM. A comparison of 2 rehabilitation programs in the treatment of acute hamstring strains. J Orthop Sports Phys Ther 2004; 34:116-25.

6. Orchard J, Best TM. The management of muscle strain injuries: an early return versus the risk of recurrence. Clin J Sport Med 2002; 12:3-5.

7. Heiderscheit BC, Sherry MA, Silder A, Chumanov ES, Thelen DG. Hamstring strain injuries: recommendations for diagnosis, rehabilitation, and injury prevention. J Orthop Sports Phys Ther 2010;40:67-81.

8. Dalton SL, Kerr ZY, Dompier TP. Epidemiology of hamstring strains in 25 NCAA sports in the 2009-2010 to 2013-2014 academic years. Am J Sports Med 2015; 43:2671-9.

9. Ekstrand J, Hägglund M, Walden M. Epidemiology of muscle injuries in professional football (soccer). Am J Sports Med.2011; 39(6):1226-32.

10. Orchard J, Best TM. The management of muscle strain injuries: an early return versus the risk of recurrence. Clin J Sport Med. 2002; 12(1):3-5.

11. Heiderscheit BC, Sherry MA, Silder A, Chumanov ES, Thelen DG. Hamstring strain injuries: recommendations for diagnosis, rehabilitation, and injury prevention. J Ortho Sports Phys Ther. 2010;40(2):67-81.

12. Malanga GA, Yan N, Stark J. Mechanisms and efficacy of heat and cold therapies for musculoskeletal injury. Postgrad Med.2015;127(1):57-65.

13. Croisier JL, Forthomme B, Namurois MH, Vanderthommen M, Crielaard JM. Hamstring muscle strain recurrence and strength performance disorders. Am J Sports Med.2002;30(2):199-203.

14. Gabriel Amorim Ramos, Gustavo Gonc, alves Arliani, et.al, Rehabilitation of hamstring muscle injuries: a literature review, rev bras or top. 2017; 5 2(1):11-16.

15. Ekstrand J, Hägglund M, Kristenson K, Magnusson H, Waldén M. Fewer ligament injuries but no preventive effect on muscle injuries and severe injuries: An 11-year follow- up of the UEFA Champions League injury study. Br J Sports Med 2013; 47:732- 7 .

16. Askling C, Lund H, Saartok T, Thorsten son A. Self- reported hamstring injuries in student- dancers. Scand J Med Sci Sports 2002; 12:230- 5.

17. Sun-Min, Jung-Hoon Lee, Effect of balance taping using kinesiology tape for a hamstring muscle injury and traumatic knee pain in an amateur university football player, Medicine (2018) 97:23(e10973).

18. Denegar C, Saliba E, Saliba S. Therapeutic Modalities for Musculoskeletal Injuries. 2nd edi. Champaign, IL: Human Kinetics. 2006. p. 119-88. 
19. Emad T Ahmed, et al. Comparative Effect of Ultrasound Therapy Versus Static Stretching on the extensibility of hamstring muscle, Int. JMed Sci Public health, 2014, $3: 468-471$.

20. Kase, K., Wallis, J. and Kase, T. (2003) Clinical Therapeutic Applications of the Kinesio Taping Method. Ken'ikai Information, Tokyo.

21. Merino-Marban R Et. Al, The Acute Effect Of Kinesio Taping On Hamstring Extensibility In University Students, Journal Of Physical Education And Sport, 2011, 11(2), Pp.23 -27.

22. Erdem Demir, Nesrin Yagc, The effect of kinesio tape and stretching on hamstring muscle flexibility, 2018, Journal of Clinical and Analytical Medicine, 45-48.

23. Lee JH, Choi SW. Balance taping; Clinical Application of Elastic Therapeutic Tape for Musculoskeletal Disorders. WE TAPE, Paju: 2016.

24. Konishi Y. Tactile stimulation with Kinesiology tape alleviates muscle weakness attributable to attenuation of Ia afferents. J Sci Med Sport 2013;16:45-8.

25. Merino, R., Mayorga, D., Fernandez, E. and Torres, G. (2010) Effect of Kinesio Taping on hip and lower trunk range of motion in triathletes. A pilot study. Journal of Sport and Health Research 2, 109-118.

26. Yoshida, A. and Kahanov, L. (2007) The Effect of Kinesio Taping on Lower Trunk Range of Motions. Research in Sport Medicine 15, 103-112.

27. Kendall, F.P. Kendall, E., Geise, P., Rodgers, M.C. and Romani, W.A. (2007) Muscles: Testing and Function, with Posture and Pain. 5th edition. Lippincott Williams \& Wilkins, United Kingdom.

28. Travell, J.G. and Simons, D.G. (2004) Travell \& Simons' Myofascial pain \& dysfunction: the trigger point manual. Volume 2 The lower extremities. Médica Panamericana, Madrid.

29. Halbertsma JP, Mulder I, Göeken LN, Eisma WH. Repeated passive stretching: acute effect on the passive muscle moment and extensibility of short hamstrings. Arch Phys Med Rehabil 1999; 80:407-14.

30. Nordez A, Cornu C, McNair P. Acute effects of static stretching on passive stiffness of the hamstring muscles calculated using different mathematical models. Clin Biomech (Bristol, Avon) 2006; 21:755-60.

31. Warren CG, Lehmann JF, Koblanski JN. Heat and stretch procedures: an evaluation using rat tail tendon. Arch Phys Med Rehabil 1976; 57:122-6.

32. Strickler T, Malone T, Garrett WE. The effects of passive warming on muscle injury. Am J Sports Med 1990; 18:141-5. 
33. Funk D, Swank A, Adams K, et al. Efficacy of moist heat pack application over static stretching on hamstring flexibility. J Strength Cond Res. 2001; 15:123-126.

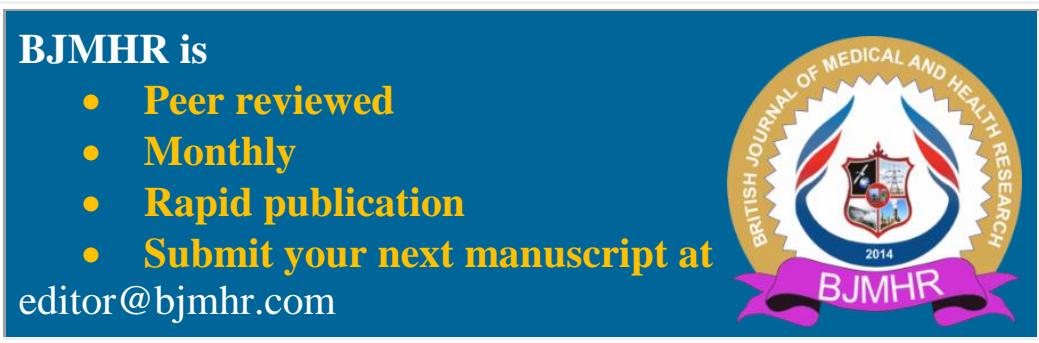

